\title{
Computational Estimation and Mathematics Education: A Narrative Literature Review
}

\author{
Paul Andrews \\ Stockholm University, Stockholm, Sweden \\ Pernille Bødtker Sunde \\ VIA University College, Arhus, Denmark, Norway \\ Mona Nosrati \\ The Mathematics Centre, NTNU, Trondheim \\ Jöran Petersson \\ Stockholm University, Stockholm, \& Malmö University, Malmö Sweden \\ Eva Rosenqvist \\ Stockholm University, Stockholm, Sweden, \\ Judy Sayers \\ The University of Leeds, Leeds, England, \\ Constantinos Xenofontos \\ The University of Stirling, Stirling, Scotland
}

Computational estimation, typically construed as an approximate mental calculation of an arithmetical problem, is an important skill in everyday life and a wide range of professional contexts. Despite its importance, textbooks and curricula address it inadequately, with the consequence that many teachers are uncertain as to why and how they should teach it. In this paper, we present a narrative literature review that brings together the extensive research of the cognitive psychologists and the limited research of the mathematics educators to clarify the nature of computational estimation and its development. Focused initially on the strategies used in computational estimation before turning to children's and adults' computational estimation competence, the review shows that computational estimation, which develops over time, draws on a wide range of strategies reciprocally dependent on a secure understanding of numbers and arithmetic. It shows that the poor estimation competence of children and adults' is susceptible to interventions, particularly with respect to addressing a common misconception that the purpose of computational estimation is the mental calculation of exact solutions.

Keywords: Computational estimation, mathematics didactics, mathematics cognition, narrative literature review 
For many everyday activities, due to its requiring less attentional resources and time (Ganor-Stern, 2018), computational estimation is often more practical than precise calculation (Bestgen et al., 1980). It is an essential life skill (Sekeris et al., 2019), particularly with respect to the evaluation of results produced by electronic calculators (Levine, 1982), dependent on both the maturity of the estimator (Lemaire \& Brun, 2014) and the complexity of the task (Dowker, 1997). Computational estimation competence is not only implicated in mathematical learning generally (Seethaler \& Fuchs, 2006; Xenidou-Dervou et al., 2018) but predicts later mathematical learning difficulties (Foegen, 2008; Jordan et al., 2003; Li et al., 2020). It has also been argued that estimation, along with reasoning in ratios and problem solving, is one of "the three most important types of mathematical thinking skills from a K-8 teacher perspective" (Sriraman \& Knott, 2009, p.206).

But what is computational estimation? Dowker (1992) describes it as "making reasonable guesses as to the approximate answers to arithmetic problems, without or before actually doing the calculation" (Ibid, p.45). Others, avoiding the ambiguity of guesswork, have equated estimation with approximation, as with Siegler and Booth's (2005) assertion that it involves "approximating the correct magnitude rather than calculating the exact answer" (p. 199). In similar vein, Ainsworth et al. (2002) suggest it is "the process of simplifying an arithmetic problem using some set of rules or procedures to produce an approximate but satisfactory answer through mental calculation" (p.28). In general, while viewing estimation and approximation as synonyms, scholars construe estimation as the application of some form of systematic procedure rather than guesswork. This makes computational estimation unique among the various forms of estimation - computational, measurement, quantity and number line (Andrews et al., 2021) - in that two individuals applying the same procedures to the same problem will always arrive at the same estimation.

Forty years ago, the superficial inclusion of computational estimation in mathematics curricula created a generation of students with limited estimational competence (Bestgen et al., 1980) and prompted the question; "Why is it that estimation is recognized by many as one of the most practically useful parts of the mathematics curriculum and yet remains perhaps the least effectively taught?" (Edwards, 1984, p.59). This problem persists with, at least in the context of the US, teachers rarely fostering estimation in their classrooms (Subramaniam, 2014), due to uncertainty as to why and how it should be taught (Joram et al., 2005). Moreover, while research has highlighted the need for interventions in the development of computational estimational competence (Peeters et al., 2016), the professional development of teachers may have been hampered by estimation being poorly addressed in textbooks (Hong et al., 2018) and the curricula within which they work, whether England, Northern Ireland, Wales or Scotland (Andrews et al., 2021), Denmark, Norway or Sweden (Sunde et al., 2021). 
By drawing together what researchers typically working in mathematical cognition have uncovered, we aim to make visible the computational estimation insights that have emerged from this work, especially for teachers and educators. Unlike the typical psychologists' review (see Block et al., 1999; Sekeris et al., 2019; Siegler et al., 2009), our interest lies more in the outcomes of cognitive processes than the cognitive processes themselves. Our review has been guided by the following question:

What has been learned from four decades of research on adults and children's engagement with computational estimation?

The methodological diversity and complexity of this computational estimation-related research, coupled with the novelty of our aim, implies a need for a narrative literature review (hereafter NLR). An NLR, as we discuss below, is especially useful for establishing the state of knowledge about a field, particularly one underpinned by diverse methodologies.

\section{Methods}

The NLR is conventionally the domain of scholars working in medical research. It is especially relevant when the reviewer's goal is to establish the state of knowledge about a field, particularly when the analysed sources draw on diverse methodologies (Ali, 2018; Boyle et al., 2014; Cronin et al., 2008; Lloyd, 2013; Phillipson et al., 2016). NLRs differ from the narrow foci of traditional systematic reviews by dint of their comprehensiveness (Boyle et al., 2014; Collins \& Fauser, 2005; Ferrari, 2015; Green et al., 2006; G. Waring et al., 2020). They have the potential to uncover issues hidden by conventional meta-analyses (Meglio \& Risberg, 2011) and trace descriptively the development of a field (Collins \& Fauser 2005; Ferrari, 2015; Minichiello et al., 2018). Moreover, while they have the potential to support practice, they are typically presented in ways that leave the reader to infer such implications (Phillipson et al., 2016; G. Waring et al., 2020) and importantly any gaps in the field. From the perspective of teaching and learning, NLRs may offer practitioners insights unlikely to be found in the reviews published in the US by the What Works Clearinghouse or in the UK by the Education Endowment Foundation. Their reviews, typically drawing explicitly on randomised studies, not only limit the well from which they draw but fail to acknowledge the importance of case study and the insights yielded by a critical mass of similar findings. Moreover, of particular relevance to this paper and further highlighting differences between an NLR and systematic reviews, Sekeris et al.'s (2019) review of the literature concerning the measurement, development, and stimulation of computational estimation in young children was limited by a precise set of objectives and a small pool of material from which to draw.

Early healthcare-related NLRs, typically due to the novelty of their qualitative emphases, were criticised for a lack of replicable rigour (Cronin et 
al., 2008). However, scholars have recently offered explicit guidance on the necessary procedures for completing an NLR (Ferrari, 2015; Gasparyan et al., 2011; Green et al., 2006; Mooring, 2016), while others, as inferred from the structure of their articles, have acknowledged the same (Batbaatar et al., 2015; Hutzler et al., 2019; Kannisto et al., 2014; Minchiello et al., 2018; Romijnders et al., 2018; Shachak \& Reis, 2009; Van Wyk et al., 2015). In essence, a good NLR will warrant the need for an investigation against clear and appropriate research questions. It will articulate not only a strategy for identifying articles but also criteria for their acceptance. It will explain the strategy for analysing the accepted literature, particularly from the perspective of keeping an open mind, and synthesise it in ways that allow key issues to emerge. Adherence to such procedures will minimise reviewer bias and the influence of preconceptions (Collins \& Fauser, 2005).

In the context of our review, a Google Scholar search on the phrase "computational estimation" anywhere in the text revealed 4330 titles. Most of these, of no relevance to this paper, referred to studies in which computational estimation was used as a tool in disciplines other than mathematics teaching and learning. For example, an early hit concerned the computational estimation of professional football players' salaries (Yaldo \& Shamir, 2017). Restricting the search to articles' titles yielded 228 hits, each of which was evaluated against the following criteria. It should

- be empirically-based, with articles presenting 'tips for teachers' excluded;

- report on the development of computational estimation-related competence or the manifestation of children's or adults' computational estimation-related competence;

- be transparently peer-reviewed;

- be available as an English full text.

These criteria reduced the number of articles to 83 , a figure rising to 107 when articles implicated by the 83 and satisfying the acceptance criteria were included. Each article was read and notes made concerning its computational estimation-related insights. This typically included our examining the material for target audience of the research, the approaches used, the outcomes and so on. These notes were read and reread with the aim of identifying and structuring the broad themes on which the following is based. Importantly, in line with the expectations of an NLR, our role was to avoid imposing any preconceptions in order to allow the material to speak for itself. A key aspect of this process, not least because the teaching and learning of mathematics is deeply culturally situated, was the need to present descriptive summaries and avoid highlighting any implications. 


\section{Results}

The process outlined above yielded three themes. These concern the

- strategies employed in computational estimation;

- development and manifestation of computational estimation in children;

- computational estimation competence of adults.

In the following we present a synthesis of the literature on each theme, followed by a discussion of those syntheses. However, as indicated earlier, we leave it to the reader to infer implications of relevance to him or her.

\section{Strategies of Computational Estimation}

Computational estimation draws on two cognitively different competences. On the one hand, estimators must create "a set of simple approximate numbers from the complex, exact ones that are given" before, on the other hand, "mentally computing the sum of these numbers in some fashion" (Case \& Sowder, 1990, p.88). Several studies of computational estimation strategies (see e.g., Dowker, 1992; Dowker et al., 1996; Hanson \& Hogan, 2000; LeFevre et al., 1993), tacitly acknowledging this duality, have drawn on the typology devised by Levine (1982). Her eight strategies, synthesised from various sources, are:

- Fractions: treating $424 \times 0.76$ as $3 / 4$ of 424 ;

- Exponents: treating $0.47 \times 0.26$ as $5 \times 10^{-1} \times 3 \times 10^{-1}$;

- Rounding both numbers: treating $25410 \div 65$ as $25000 \div 60$;

- Rounding one number: treating $93 \times 18$ as $93 \times 20$;

- Powers of 10: treating $76 \times 89$ as $100 \times 100$;

- Known numbers: treating $1293 \div 71$ as $1300 \div 65$, which yields a simple calculation;

- Incomplete partial products: treating $25410 \div 65$ as $(25400 \div 60)$ plus $(10 \div 5)$

- Proceeding algorithmically: treating $64.6 \times 0.16$ as $646 \times 10$ plus $646 \times 6$ and adjusting the answer accordingly.

Others have proposed truncation as an alternative to rounding, whereby digits to the right of a number are replaced by zeros, so that 463 times 58 would become 400 times 50 (Lemaire et al., 2000). Interestingly, recent analyses of several European mathematics curricular documents found that the only estimation-related strategy mentioned was rounding as a learning outcome in its own right rather than as a support to estimation (Andrews et al., 2021; Sunde et al., 2021). That being said, other studies of the early 1980s, typically investigating the strategies of competent estimators, have identified more general cognitive processes as a means of simplifying communication between researchers and, importantly, teachers. The best known of these is the 
work by R. Reys, et al. (1982), which identified three such processes, which subsume Levine's (1982) strategies. These are reformulation, where numerical data may be changed to create a more manageable form but which leaves the structure of the problem intact; translation, a process in which the structure of the problem is changed to produce a more manageable form, and compensation, a process where the estimator makes numerical adjustments prompted by translations or reformulations (R. Reys et al., 1982). These three processes have been shown to account for the strategies used by estimators of all ages in various cultural contexts; as shown in studies of Canadian adults and fourth, sixth and eighth grade students (LeFevre et al., 1993), Japanese fifth and eighth grade students (R. Reys et al., 1991), Kuwaiti primary and middle-school teachers (Alajmi, 2009), Mexican grade five and eight students (B. Reys et al., 1991), Turkish grade seven students (Boz \& Bulut, 2012) and US grade three, five, seven and nine students (Sowder \& Wheeler, 1989). These tendencies have been confirmed by a recent review of research on the computational estimation strategies of kindergarten and primary aged children (Sekeris, et al., 2019). Moreover, these studies have also shown how the majority of strategies employed by children can be subsumed under reformulation in ways that reflect an increasing sophistication and accuracy with age.

\section{The Computational Estimation of Children}

The following section, mainly due to the greater attention paid to it by researchers, is the most extensive. In order to facilitate the reader's journey, it has been presented in three sub-sectioned, each of which addresses a different aspect of children's computational estimation.

\section{Children's Computational Estimation Competence}

Unsurprisingly, children's computational estimation competence, whether additive (Lemaire \& Lecacheur, 2011) or multiplicative (Liu, 2009) develops with age. An early interview study found, across the age range 1115 , limited conceptions of estimation, with, for example, fewer than one fifth recognising that $789 \times 0.52$ is appropriately estimated by halving 800 (Sowder, 1984). A later study found, across grades 3, 5, 7, and 9, a growing awareness of why estimation matters and an emergent recognition of the need to compensate for rounding errors, although the idea of rounding-thencomputing rather than computing-then-rounding was slow to develop (Sowder \& Wheeler, 1989). Similar findings emerged from a study of children's multiplicative estimation in grades 4,6 and 8 , whereby a cognitive shift seemed to occur at around grade 6 as children began to understand the role of simplification in their estimations (LeFevre et al., 1993). Other studies have found that eighth-graders are more competent estimators when working with integers rather than decimals and when tasks are additive rather than multiplicative (Rubenstein, 1985). Moreover, with respect to multiplication, 
children are more efficient estimators when tasks are presented visually rather than orally (Liu, 2009), although Rubenstein (1985) found no difference between tasks presented symbolically and verbally. Finally, highlighting potential limitations in their learning experiences, children in grade 4 tend to equate estimation with guesswork, while by grade six they see it as rounding (LeFevre et al., 1993).

Early cross-sectional studies of American children highlighted a problem for curriculum developers and teachers alike. Drawing on samples from national assessments, Carpenter et al. (1984) found, at ages 9, 13 and 17, that American children's performance on computational estimation was significantly worse than their exact computation of the same problem. This was due, in part, to their being unable to perform the mental calculations necessary for successful estimation (Carpenter et al., 1984). Moreover, in their study of children in grades 3, 5, 7, and 9, Sowder and Wheeler (1989) found older children were uncomfortable with the processes of estimation, being particularly reluctant to accept the validity of multiple estimates. Sowder (1984) had previously argued that a major part of the problem was an educational experience that privileged correct answers, typically derived from the application of algorithms taught to produce correct answers. She commented that the "requirement that these problems be done without a pencil in hand was a difficult one for students to accept" (Sowder, 1984, p.335). Other studies have continued to highlight the problems students have in understanding computational estimation as an efficient alternative to an exact calculation. For example, in a study of Chinese third and fifth grade students' multiplication-related estimation, Liu (2009) found that, while grade five students were better estimators than grade three students, the latter tended to exploit rounding-related strategies while the former resorted to the mental application of standard written algorithms, particularly when the distance between the unit of a number and its nearest decade was great. Similar findings have emerged from studies of Japanese fifth- and eighth-grade students, whose computational estimations not only improve with age but invoke the three general cognitive processes of reformulation, translation, and compensation. However, their tendency to use paper-and-pencil procedures mentally often interfered with the estimation process (R. Reys et al., 1991). Other studies have found that mathematical anxiety has limited impact on the accuracy of grade-four and grade-six Chinese students' additive estimations, with, irrespective of anxiety level, both accuracy and speed improving with age. The important differences were that low anxiety students were more rapid and high anxiety students tended to employ rounding down (Si et al., 2016).

With respect to their computational estimation strategies, a relatively early American study found that children in grades five through eight appeared conditioned to round numbers to the nearest leading power of 10 , even when more efficient and accurate processes were available (Schoen et al., 1990). Over the last twenty years, much research on children's 
computational estimation-related strategies has been conducted by Lemaire and his colleagues in relation to French children's strategies for estimating two-and three-digit addition problems. For example, Lemaire et al. (2000) investigated the free-choice estimation strategies of ten-year old children and found four dominant strategies, typically involving rounding and decomposition in different ways. However, the important findings were that children chose strategies adaptively and that "the fastest strategy was truncation and the slowest was compensation... (although) compensation yielded the most accurate estimates and rounding without decomposition and truncation yielded the least accurate estimates" (p.145). In similar vein, Lemaire and Lecacheur (2002) found, with respect to grade four and six children, that while estimations became more adaptive with age, rounding down remained the most commonly used strategy. More recently, Lemaire and Lecacheur (2011) confirmed that third, fifth and seventh grade students' strategy choice and estimation accuracy improved with age. In addition to confirming increasing speed and accuracy, Lemaire and Brun's (2014) study of third- and fifth-grade students, found the proportion of students using the same strategy decreasing with age. Moreover, when the time between successive tasks was lengthened, previously inefficient strategies were replaced by better ones, indicating that children were able to reflect on and adapt their approaches. Finally, Hammerstein et al. (2019), in a metacognition-related study, examined third- and fourth-graders' estimates in relation to their ability to keep track of relevant and irrelevant task components. They found that most children choose the more efficient strategy of two imposed strategy choices, but of the remainder, rounding down is more frequently chosen than rounding up. However, the key finding was children who are able to manage the different task components show higher levels of strategy flexibility, strategy adaptivity and strategy performance.

Other studies, typically undertaken in East Asian contexts, have yielded complementary results. For example, Yang's (2005) interview study of Taiwanese sixth-grade students found that "most of these students showed no estimation strategies and were inclined to simply use written algorithms" (Yang, 2005, p.331). This latter point seems to be deep-seated, with children frequently uncertain as to how to estimate. For example, R. Reys and Yang (1998) found that Taiwanese sixth grade students were not only significantly more competent with precise calculation than estimation but even tasks with an obvious benchmark failed to elicit its use. More recently, Yang and $\mathrm{Wu}$ (2012) examined the computational estimation strategies used by eighth-grade Taiwanese students when solving comparable contextual and numerical problems. They found that students completed successfully significantly more numerical problems than contextualised problems. In addition, they found that students employed reformulation, translation and compensation in significantly greater proportions for numerical problems than contextual. However, irrespective of problem type, students still tended to use algorithms 
rather than the requested estimation. Koyama (1994) conducted a study of fourth-, fifth- and sixth- grade Japanese children and found, with respect to estimation to the division of 456 by 87 , that few students in each grade were able to recognise that the 'nice' numbers 450 and 90 yielded an efficient and simply executed solution. On the other hand, Li et al. (2020) conducted a study comparing low-achieving and normally-achieving Chinese fifth- and sixth-grade students and found normally achieving students, with respect to estimations of two-digit addition problems, were more flexible and able to manage switching strategies than the low-achieving students, particularly with respect to rounding up.

\section{Children's Computational Estimation and Researchers'Methodologies}

Scholars have employed a variety of methodological approaches when researching children's computational estimation. A number have exploited tasks involving reference numbers, whereby children are invited to estimate whether the result of a calculation would be greater or less than a given reference number. For example, Ganor-Stern (2016) found, with respect to fourth grade and sixth grade students and adults, that speed and accuracy increased with age. Also, estimations were more accurate across all ages when the true answer was greater than the reference number and when the reference number was far from the true answer. Moreover, with increasing age, the impact of near and far reference points with respect to speed and accuracy diminished. A later study, drawing on reference numbers and two-digit multiplication problems, found that accuracy tends to plateau at grade four, although response times continue to decrease into adulthood (Ganor-Stern, 2018). In similar vein, a longitudinal study of grade one and grade two children found that a measure of computational estimation based on reference number tasks uniquely predicted children's broader mathematical growth (Xenidou-Dervou et al., 2018). Furthermore, Caviola et al. (2012) found, from tasks whereby grade three and four children had to identify the closer of two given answers to the actual value of an addition problem, that estimations make greater demands on working memory than exact calculations.

Other studies have exploited multiple choice tasks, whereby participants are invited to select one answer from several possibilities as an estimation to a given calculation. For example, LeFevre et al. (1993) examined children's responses to multiple choice estimations of both pure number tasks and word problems. They found accuracy increased with age, although across grades accuracy diminished with increasing task complexity. Also, children in grade eight were more accurate estimating word problems than number problems, with the opposite being the case for those in grade six. Other investigations found computational estimation competence to be a robust indicator, across grades six through eight, of mathematics achievement in general, problem solving, and reasoning and mathematical communication in particular (Foegen \& Deno, 2001). In a later study, Foegen (2008) found 
computational estimation to be a strong proxy for mathematics attainment at grade six, although this tended to reduce as children became older. In short, computational estimation seems a strong predictor of those aspects of mathematical competence related to flexibility.

Other studies, exploiting simplified multiple-choice tasks whereby children select the closer of two feasible estimates to various addition and subtraction problems, have compared the mathematics cognition of children with learning difficulties with normally achieving children. In one study, comparisons were made between grade two children with mathematical difficulties (MD), children with reading difficulties (RD), children with both difficulties (MD/RD) and normally achieving children (NA). The study found that both $\mathrm{MD}$ and $\mathrm{MD} / \mathrm{RD}$ children were significantly poorer estimators than children in the NA and RD groups. Indeed, the equivalence of these latter groups tends to confirm that understanding and undertaking computational estimation is a language-independent competence (Hanich et al., 2001). A second study also found that children with reading difficulties were equally competent estimators as normally achieving children. However, the same study also found "that growth on approximate calculation was relatively flat across achievement groups, indicating that this task was hard for all children" (Jordan et al., 2003, p.847).

\section{Children's Computational Estimation and Teaching Interventions}

Although space prevents a detailed summary of their procedures, a small number of studies have reported interventions designed to improve children's computational estimation-related competence. These include Bobis' (1991) successful intervention with Australian grade-five children, which involved fifteen weeks of instruction during which children undertook various activities concerning mental calculation and estimation relating to multiplication and division algorithms. In England, Ainsworth et al. (2002), used computer-based interventions to develop year-five children's computational estimation competence. They found that the use of either, but not both, pictorially-represented tasks or symbolically represented tasks improved children's confidence and accuracy in their computational estimations of two- and three-digit arithmetic tasks. Two USA-based interventions also showed improvements in children's computational estimation competence. First, Hurley et al. (2005), undertook an intervention, based on the use of a "nice number computational estimation strategy", whereby numbers are rounded to the nearest nice number before being subjected to mental calculation. Participants either worked alone or in groups of three. Children in groups became significantly more efficient estimators than the children working alone. Second, Star and Rittle-Johnson (2009) found that ten-year-old children who were asked to compare two estimations to a problem simultaneously became more flexible estimators than those children who compared the estimations sequentially. Also, while rounding 
both numbers was the most frequently used strategy by both groups of children, before and after interventions, children in the comparison group used truncation more often than students in the sequential condition.

\section{The Computational Estimation Competence of Adults}

With respect to adults' computational estimation competence, a study of mathematicians, accountants, undergraduates in psychology and undergraduates in English found the mathematicians to be the most efficient estimators and the English undergraduates the least efficient (Dowker et al., 1996). The competence of the English undergraduates accords with similar studies, which have found acceptable levels of undergraduate competence with respect to addition and subtraction of integers but declining levels with respect to multiplication and division and any task involving fractions or decimals (Goodman, 1991; Hanson \& Hogan, 2000; R. Waring \& PennerWilger, 2017). Further, studies comparing adults' computational estimations with their exact calculations, typically find higher levels of competence with the latter than the former (Hanson \& Hogan, 2000; Kalaman \& LeFevre, 2007; R. Waring \& Penner-Wilger, 2017), reflecting a lack of confidence and familiarity with the reasons for and processes of computational estimation. Finally, Chinese-educated adults are more rapid and accurate estimators than Flemish-educated adults, although the latter are more adaptive in their strategy choices (Imbo \& LeFevre, 2011). In similar vein, with respect to two-digit multiplication estimation tasks, Chinese-educated undergraduates, who were more competent on exact calculations, were more likely to choose optimal estimation procedures in a free-choice situation than Canadian educated undergraduates. However, when instructed to respond speedily, both groups identified the optimum strategy in around $60 \%$ of cases, a figure that exceeded $90 \%$ when the instruction focused on accuracy. The authors conclude, as a pointer to those who teach estimation, that "providing explicit instructions and feedback can greatly influence participants' procedure choices, and hence offers interesting implications for educational settings" (Xu et al., 2014, p.1491).

Interestingly, most studies of adults' computational estimation have focused on multi-digit multiplication (Ardiale \& Lemaire, 2012; 2013; GanorStern, 2015, 2017, 2018; Ganor-Stern \& Weiss, 2016; Imbo \& Lefevre, 2011; Lemaire \& Lecacheur, 2010; Lemaire et al., 2004; Liu, 2013; Taillan et al., 2015; Xu et al., 2014). Of these, Lemaire and his colleagues have examined young and old adults' computational estimation in various contexts. Older adults, whose choice of estimation strategy is less flexible than that of young adults, tend to provide less accurate estimates and take more time than younger adults (Lemaire et al., 2004; Taillan et al., 2015). Under timed conditions and directed to first use a researcher-defined inefficient strategy, most adults are able to recognise the need to switch to an efficient and more accurate strategy; although, despite being considerably less competent with 
exact calculations, younger adults tend to make more strategy switches more rapidly than older adults (Ardiale \& Lemaire, 2012, 2013; Taillan et al., 2015). Moreover, irrespective of the conditions, rounding up takes more time than rounding down (Lemaire \& Lecacheur, 2010, Taillan et al., 2015). Indeed, a study of undergraduates' computational estimation of two-digit multiplication found that when working memory was distracted by an imposed task unrelated to estimation, participants not only made poorer estimations but rounded down more often than rounded up (Imbo et al., 2007).

A particular set of studies has exploited multi-digit multiplication as the context for investigating the impact of reference numbers on adults' computational estimation. Participants were presented with a calculation and asked to estimate whether the exact answer would be larger or smaller than a given (reference) number. Undergraduate students were found to be faster and more accurate when reference numbers were either far from the exact answer or, irrespective of distance, smaller than it (Ganor-Stern, 2015). A second study showed that while dyscalculic adults' computational estimations were less accurate than a control group's, their accuracy remained well above the level of chance (Ganor-Stern, 2017). A further study found that practice on reference number-related computational estimation improves performance (Ganor-Stern \& Weiss, 2016), while another found that older adults, who are slower and slightly more accurate estimators than young adults, are less affected by the distance between the reference number and the exact answer (Ganor-Stern, 2018).

With respect to teacher education students, research typically derives from the USA. One multiplication study found estimations typically within $40 \%$ of the true value and that neither response times nor accuracy were affected by the complexity of the numbers involved (Liu, 2013). Another study, involving a wide range of estimation tasks, found US primary teacher education students achieving barely 50\% levels of proficiency on a "range of answers determined by the investigator" (Goodman, 1991, p.260), although tasks involving reference numbers were more successfully addressed than other forms and application problems were better addressed than purely numerical. These results resonate with a later study, where integer-based tasks were substantially better addressed than fraction-based (Tsao, 2013). Finally, while the pre-test of a recent intervention study found poor levels of computational estimation competence, the post-test showed students' competence had improved, although it remained limited with respect to decimals and fractions (Son et al., 2019). This latter study, alluding to another important area of research, also found that students' "estimation performance was significantly related to their self-reported math knowledge and their views on estimation in teaching mathematics", while those "who perceived the meaning of estimation from the purpose perspectives outperformed those who perceived it from the process perspectives on estimation tests" (Son et al., 2019, p.691). In similar vein, Tsao (2013) found teacher education students' 
attitudes correlated positively with performance. That being said, and shifting attention from the US, more than $60 \%$ of Kuwaiti elementary teachers construe computational estimation as rounding, while two-thirds view it as an important life-skill and only one-fifth (20\%) see it as playing a role in mathematics education (Alajmi, 2009).

\section{Discussion and Conclusions}

A key function of a narrative literature review is to present a descriptive account of the state of knowledge about a field. Our view, acknowledging limitations of space, is that we have achieved that goal in ways that should allow teachers and teacher educators to infer implications of relevance to them. It has also, as predicted by Hogan and Brezinski (2003), highlighted the problem for mathematics educators created by the methodological approaches of the psychologists. The latter have typically restricted participants' strategies, prescribing either a rounding up of both operands or a rounding down (see Imbo \& LeFevre, 2010; Lemaire \& Brun, 2014; Lemaire \& Lecacheur, 2002; Li et al., 2020). Indeed, participants in Hammerstein et al.'s (2019) study were expressly forbidden from using a mixed strategy, whereby one operand would be rounded up and the other rounded down, an approach ideal for estimating, say, $78 \times 23$. In short, many psychological studies, driven by the need for replicable methodologies, have employed narrow operationalisations of computational estimation that make the interpretation of their results difficult for those looking for insights related to teaching and learning.

That being said, the available evidence has shown that being a successful computational estimator requires "knowledge of multiple strategies and the ability to select the most appropriate strategy for a given problem and a given problem-solving goal" (Star et al., 2009, p. 570). The same evidence also suggests that trying to categorise all computational estimation-related strategies may be less productive than searching for broader categorisations that are simple to define and operationalise. For example, Dowker's (1992) investigation of professional mathematicians found every participant invoking multiple approaches to most problems, one as many as 23 , while 42 of her 44 informants used an approach unique to the individual for at least one problem. Importantly, the extent of this variation, which is likely to be of considerable interest to researchers, may be problematic for teachers, who, while needing to be mindful of its existence, may be better served by attending to the three processes of reformulation, translation and compensation ( $R$. Reys et al., 1982).

In general, adults' computational estimation competence is poor (Anestakis \& Lemonidis, 2014; Levine, 1982), even among psychology undergraduates (Ganor-Stern, 2015; Xu et al., 2014), not least because many, particularly older, do not understand the rationale for estimating and are more 
accurate with exact calculations (Hanson \& Hogan, 2000; Kalaman \& LeFevre, 2007; R.Waring \& Penner-Wilger, 2017). Indeed, adults who understand the purpose of computational estimation are better estimators than those who only understand it as a process (Son et al., 2019). Adults' computational estimation is influenced by age and mathematics anxiety ( $\mathrm{Si}$ et al., 2016), as well as cultural context (Imbo \& LeFevre, 2011). Beyond any obvious sense of real-world application, measures of computational estimation are correlated positively with mathematical knowledge (Son et al., 2019; R.Waring \& Penner-Wilger, 2017), mathematics self-concept (Gliner, 1991), personal independence (Hogan \& Parlapiano, 2008) and, bizarrely, negatively correlated with measures of agreeableness (Hogan et al., 2004).

Children's computational estimation, which is closely related to the different stages of cognitive development identified by Neo-Piagetian researchers (Case \& Sowder, 1990), is a function of their arithmetical competence to the extent that their estimations become less accurate the further a task strays from their base-line arithmetical competence (Dowker, 1997; Seethaler \& Fuchs, 2006). Moreover, for many students, irrespective of geographical location, computational estimation is an unfamiliar activity to the extent that simply asking them to provide an estimate when an exact answer is within their mental computation capability is likely to fail (Liu, 2009). Importantly, children with access to a range of estimation strategies, including the ability to switch when one strategy seems to be failing, are not only more successful learners of mathematics but more accurate estimators than students with access to few strategies (Li et al., 2020; Star et al., 2009). In this respect, there seems to be a strong reciprocal relationship between computational estimation competence and those aspects of mathematical competence related to flexibility (Foegen, 2008; Hammerstein et al., 2019).

In closing, having presented a descriptive summary of the state of knowledge of the field, we invite colleagues to consider how the teaching and learning of computational estimation may be improved in their particular cultural contexts. In so doing, we remind colleagues that computational estimation's inadequate representation in national curricula and school textbooks necessarily force one to look elsewhere for guidance. We also remind colleagues that while many learners fail to understand the nature of estimation, many of the findings of the psychologists have been tempered by narrow operationalisations of estimation. What seems clear, however, is that if learners are to acquire both strategic flexibility and an understanding of why computational estimation matters, then regular interventions are necessary. That said, research on estimation-related teaching interventions remains an underdeveloped field. 


\section{References}

Ainsworth, S., Bibby, P., \& Wood, D. (2002). Examining the effects of different multiple representational systems in learning primary mathematics. Journal of the Learning Sciences, 11(1), 25-61

Alajmi, A. (2009). Addressing computational estimation in the Kuwaiti curriculum: Teachers' views. Journal of Mathematics Teacher Education, 12(4), 263-283.

Ali, E. (2018). Women's experiences with postpartum anxiety disorders: A narrative literature review. International Journal of Women's Health, 10, 237-249.

Andrews, P., Xenofontos, C., \& Sayers, J. (2021). Estimation in the primary mathematics curricula of the United Kingdom: Ambivalent expectations of an essential competence. International Journal of Mathematics Education in Science and Technology. Advance online publication https://doi.org/10.1080/0020739X.2020.1868591.

Anestakis, P., \& Lemonidis, C. (2014). Computational estimation in an adult secondary school: A teaching experiment. MENON: Journal of Educational Research, Thematic Issue Number 1, 28-45.

Ardiale, E., \& Lemaire, P. (2012). Within-item strategy switching: An age comparative study in adults. Psychology and Aging, 27(4), 1138-1151.

Ardiale, E., \& Lemaire, P. (2013). Effects of execution duration on withinitem strategy switching in young and older adults. Journal of Cognitive Psychology, 25(4), 464-472.

Azaola, M. (2019). Support from extended family in higher education: A narrative literature review. Journal of Further and Higher Education, 44(1), 1-15.

Batbaatar, E., Dorjdagva, J., Luvsannyam, A., \& Amenta, P. (2015). Conceptualisation of patient satisfaction: A systematic narrative literature review. Perspectives in Public Health, 135(5), 243-250.

Bestgen, B., Reys, R., Rybolt, J., \& Wyatt, J. (1980). Effectiveness of systematic instruction on attitudes and computational estimation skills of preservice elementary teachers. Journal for Research in Mathematics Education, 11(2), 124-136.

Block, R., Zakay, D., \& Hancock, P. (1999). Developmental changes in human duration judgments: A meta-analytic review. Developmental Review, 19(1), 183-211.

Bobis, J. (1991). The effect of instruction on the development of computational estimation strategies. Mathematics Education Research Journal, 3(1), 17-29.

Boyle, E., MacArthur, E., Connolly, T., Hainey, T., Manea, M., Kärki, A., \& van Rosmalen, P. (2014). A narrative literature review of games, animations and simulations to teach research methods and statistics. Computers \& Education, 74, 1-14. 
Boz, B., \& Bulut, S. (2012). A case study about computational estimation strategies of seventh graders. Elementary Education Online, 11(4), 979994.

Carpenter, T., Matthews, W., Lindquist, M., \& Silver, E. (1984). Achievement in mathematics: Results from the national assessment. The Elementary School Journal, 84(5), 485-495.

Case, R., \& Sowder, J. (1990). The development of computational estimation: A neo-Piagetian analysis. Cognition and Instruction, 7(2), 79-104.

Caviola, S., Mammarella, I., Cornoldi, C., \& Lucangeli, D. (2012). The involvement of working memory in children's exact and approximate mental addition. Journal of Experimental Child Psychology, 112(2), $141-160$.

Collins, J., \& Fauser, B. (2005). Balancing the strengths of systematic and narrative reviews. Human Reproduction Update, 11(2), 103-104.

Cronin, P., Ryan, F., \& Coughlan, M. (2008). Undertaking a literature review: A step-by-step approach. British Journal of Nursing, 17(1), 38-43.

Dowker, A. (1992). Computational estimation strategies of professional mathematicians. Journal for Research in Mathematics Education, 23(1), 45-55.

Dowker, A. (1997). Young children's addition estimates. Mathematical Cognition, 3(2), 140-153

Dowker, A., Flood, A., Griffiths, H., Harriss, L., \& Hook, L. (1996). Estimation strategies of four groups. Mathematical Cognition, 2(2), $113-135$.

Edwards, A. (1984). Computational estimation for numeracy. Educational Studies in Mathematics, 15(1), 59-73.

Ferrari, R. (2015). Writing narrative style literature reviews. Medical Writing, 24(4), 230-235.

Foegen, A. (2008). Progress monitoring in middle school mathematics: Options and issues. Remedial and Special Education, 29(4), 195-207.

Foegen, A., \& Deno, S. (2001). Identifying growth indicators for lowachieving students in middle school mathematics. The Journal of Special Education, 35(1), 4-16.

Ganor-Stern, D. (2015). When you don't have to be exact: Investigating computational estimation skills with a comparison task. Acta Psychologica, 154, 1-9.

Ganor-Stern, D. (2016). Solving math problems approximately: A developmental perspective. PLoS ONE, 11(5), Article e0155515. https://doi.org/10.1371/journal.pone.0155515.

Ganor-Stern, D. (2017). Can dyscalculics estimate the results of arithmetic problems? Journal of Learning Disabilities, 50(1), 23-33.

Ganor-Stern, D. (2018). Do exact calculation and computation estimation reflect the same skills? Developmental and individual differences 
perspectives. Frontiers in Psychology, 9 (Article 1316). https://doi.org/10.3389/fpsyg.2018.01316.

Ganor-Stern, D., \& Weiss, N. (2016). Tracking practice effects in computation estimation. Psychological Research, 3, 434.

Gasparyan, A. Y., Ayvazyan, L., Blackmore, H., \& Kitas, G. D. (2011). Writing a narrative biomedical review: Considerations for authors, peer reviewers, and editors. Rheumatology International: Clinical and Experimental Investigations, 31(11), 1409.

Gliner, G. (1991). Factors contributing to success in mathematical estimation in preservice teachers: Types of problems and previous mathematical experience. Educational Studies in Mathematics, 22(6), 595-606.

Green, B., Johnson, C., \& Adams, A. (2006). Writing narrative literature reviews for peer-reviewed journals: Secrets of the trade. Journal of Chiropractic Medicine, 5(3), 101-117.

Goodman, T. (1991). Computational estimation skills of pre $\square$ service elementary teachers. International Journal of Mathematical Education in Science and Technology, 22(2), 259-272.

Hammerstein, S., Poloczek, S., Loesche, P., Lemaire, P., \& Buettner, G. (2019). Effects of working memory updating on children's arithmetic performance and strategy use: A study in computational estimation. Journal of Experimental Child Psychology, 184, 174-191.

Hanich, L., Jordan, N., Kaplan, D., \& Dick, J. (2001). Performance across different areas of mathematical cognition in children with learning difficulties. Journal of Educational Psychology, 93(3), 615-626.

Hanson, S., \& Hogan, T. (2000). Computational estimation skill of college students. Journal for Research in Mathematics Education, 31(4), 483499.

Hogan, T., \& Brezinski, K. (2003). Quantitative estimation: One, two, or three abilities? Mathematical Thinking and Learning, 5(4), 259-280.

Hogan, T., \& Parlapiano, C. (2008). Personality factors related to quantitative estimation skill: Confirmation and extension. Psychological Reports, 103(1), 189-198.

Hogan, T., Wyckoff, L., Krebs, P., Jones, W., \& Fitzgerald, M. (2004). Tolerance for error and computational estimation ability. Psychological Reports, 94(3 suppl), 1393-1403.

Hong, D., Choi, K., Runnalls, C., \& Hwang, J. (2018). Do textbooks address known learning challenges in area measurement? A comparative analysis. Mathematics Education Research Journal, 30(3), 325-354.

Hurley, E., Boykin, A., \& Allen, B. (2005). Communal versus individual learning of a math-estimation task: African American children and the culture of learning contexts. The Journal of Psychology, 139(6), 513527.

Hutzler, Y., Meier, S., Reuker, S., \& Zitomer, M. (2019). Attitudes and selfefficacy of physical education teachers toward inclusion of children with 
disabilities: A narrative review of international literature. Physical Education and Sport Pedagogy, 24(3), 249-266.

Imbo, I., Duverne, S., \& Lemaire, P. (2007). Working memory, strategy execution, and strategy selection in mental arithmetic. Quarterly Journal of Experimental Psychology, 60(9), 1246-1264.

Imbo, I., \& LeFevre, J.-A. (2010). The role of phonological and visual working memory in complex arithmetic for Chinese- and Canadianeducated adults. Memory \& Cognition, 38(2), 176-185.

Imbo, I., \& LeFevre, J.-A. (2011). Cultural differences in strategic behavior: A study in computational estimation. Journal of Experimental Psychology: Learning, Memory, and Cognition, 37(5), 1294-1301.

Joram, E., Gabriele, A., Bertheau, M., Gelman, R., \& Subrahmanyam, K. (2005). Children's use of the reference point strategy for measurement estimation. Journal for Research in Mathematics Education, 36(1), 423.

Jordan, N., Hanich, L., \& Kaplan, D. (2003). A longitudinal study of mathematical competencies in children with specific mathematics difficulties versus children with comorbid mathematics and reading difficulties. Child Development, 74(3), 834-850.

Kalaman, D., \& Lefevre, J.-A. (2007). Working memory demands of exact and approximate addition. European Journal of Cognitive Psychology, 19(2), 187-212.

Kannisto, K. A., Koivunen, M. H., \& Välimäki, M. A. (2014). Use of mobile phone text message reminders in health care services: A narrative literature review. Journal of Medical Internet Research, 16(10), e222. https://doi.org/10.2196/jmir.3442.

Koyama, M. (1994). Research into relationship between the computational estimation ability and strategy and the mental computation ability: Analysis of a survey of the fourth, fifth and sixth graders in Japan. Hiroshima Journal of Mathematics Education, 2, 35-44.

LeFevre, J.-A., Greenham, S., \& Waheed, N. (1993). The development of procedural and conceptual knowledge in computational estimation. Cognition and Instruction, 11(2), 95-132.

Lemaire, P., Arnaud, L., \& Lecacheur, M. (2004). Adults' age-related differences in adaptivity of strategy choices: Evidence from computational estimation. Psychology and Aging, 19(3), 467-481.

Lemaire, P., \& Brun, F. (2014). Effects of strategy sequences and responsestimulus intervals on children's strategy selection and strategy execution: A study in computational estimation. Psychological Research, 78(4), 506-519.

Lemaire, P., Lecacheur, M., \& Farioli, F. (2000). Children's strategy use in computational estimation. Canadian Journal of Experimental Psychology, 54(2), 141-148. 
Lemaire, P., \& Lecacheur, M. (2002). Children's strategies in computational estimation. Journal of Experimental Child Psychology, 82(4), 281-304.

Lemaire, P., \& Lecacheur, M. (2010). Strategy switch costs in arithmetic problem solving. Memory and Cognition, 38(3), 322-332.

Lemaire, P., \& Lecacheur, M. (2011). Age-related changes in children's executive functions and strategy selection: A study in computational estimation. Cognitive Development, 26(3), 282-294.

Levine, D. (1982). Strategy use and estimation ability of college students. Journal for Research in Mathematics Education, 13(5), 350-359.

Li, H., Hua, X., Yang, Y., Huang, B., \& Si, J. (2020). How does task switching affect arithmetic strategy use in children with low mathematics achievement? Evidence from computational estimation. European Journal of Psychology of Education, 35(1), 225-240.

Liu, F. (2009). Computational estimation performance on whole-number multiplication by third- and fifth-grade Chinese students. School Science and Mathematics, 109(6), 325-337.

Liu, F. (2013). Are exact calculation and computational estimation categorically different? Applied Cognitive Psychology, 27(5), 672-682.

Lloyd, C. (2013). The stigmatization of problem drug users: A narrative literature review. Drugs: Education, Prevention and Policy, 20(2), 8595.

Meglio, O., \& Risberg, A. (2011). The (mis)measurement of M\&A performance-A systematic narrative literature review. Scandinavian Journal of Management, 27(4), 418-433.

Minichiello, A., Hood, J. R., \& Harkness, D. S. (2018). Bringing user experience design to bear on STEM education: A narrative literature review. Journal for STEM Education Research, 1(1), 7-33.

Mooring, Q. (2016). Recruitment, advising, and retention programs Challenges and solutions to the international problem of poor nursing student retention: A narrative literature review. Nurse Education Today, 40, 204-208.

Peeters, D., Degrande, T., Ebersbach, M., Verschaffel, L., \& Luwel, K. (2016). Children's use of number line estimation strategies. European Journal of Psychology of Education, 31(2), 117-134.

Phillipson, L., Goodenough, B., Reis, S., \& Fleming, R. (2016). Applying knowledge translation concepts and strategies in dementia care education for health professionals: Recommendations from a narrative literature review. Journal of Continuing Education in the Health Professions, 36(1), 74-81.

Reys, R., Rybolt, J., Bestgen, B., \& Wyatt, J. (1982). Processes used by good computational estimators. Journal for Research in Mathematics Education, 13(3), 183-201.

Reys, R., Reys, B., Nohda, N., Ishida, J., Yoshikawa, S., \& Shimizu, K. (1991). Computational estimation performance and strategies used by 
fifth- and eighth-grade Japanese students. Journal for Research in Mathematics Education, 22(1), 39-58.

Reys, B., Reys, R., \& Peñafiel, A. (1991). Estimation performance and strategy use of Mexican 5th and 8th grade student sample. Educational Studies in Mathematics, 22(4), 353-375.

Reys, R., \& Yang, D.-C. (1998). Relationship between computational performance and number sense among sixth- and eighth-grade students in Taiwan. Journal for Research in Mathematics Education, 29(2), 225237.

Romijnders, K., van Osch, L., de Vries, H., \& Talhout, R. (2018). Perceptions and reasons regarding e-cigarette use among users and non-users: A narrative literature review. International Journal of Environmental Research and Public Health, 15(6), 1190.

Rubenstein, R. (1985). Computational estimation and related mathematical skills. Journal for Research in Mathematics Education, 16(2), 106-119.

Schoen, H., Blume, G., \& Hoover, H. (1990). Outcomes and processes on estimation test items in different formats. Journal for Research in Mathematics Education, 21(1), 61-73.

Seethaler, P., \& Fuchs, L. (2006). The cognitive correlates of computational estimation skill among third-grade students. Learning Disabilities Research \& Practice, 21(4), 233-243.

Sekeris, E., Verschaffel, L., \& Luwel, K. (2019). Measurement, development, and stimulation of computational estimation abilities in kindergarten and primary education: A systematic literature review. Educational Research Review, 27, 1-14.

Shachak, A., \& Reis, S. (2009). The impact of electronic medical records on patient-doctor communication during consultation: A narrative literature review. Journal of Evaluation in Clinical Practice, 15(4), 641-649.

Si, J., Li, H., Sun, Y., Xu, Y., \& Sun, Y. (2016). Age-related differences of individuals' arithmetic strategy utilization with different level of math anxiety. Frontiers in Psychology, 7, 1612-1612.

Siegler, R., \& Booth, J. (2005). Development of numerical estimation: A review. In J. Campbell (Ed.), Handbook of mathematical cognition. (pp. 197-212). New York: Psychology Press.

Siegler, R., Thompson, C., \& Opfer, J. (2009). The logarithmic-to-linear shift: One learning sequence, many tasks, many time scales. Mind, Brain, and Education, 3(3), 143-150.

Son, J.-W., Hu, Q., \& Lim, W. (2019). Computational estimation skill of preservice teachers: Operation type and teacher view. International Journal of Mathematical Education in Science and Technology, 50(5), 682-706.

Sowder, J. (1984). Computational estimation procedures of school children. The Journal of Educational Research, 77(6), 332-336. 
Sowder, J., \& Wheeler, M. (1989). The development of concepts and strategies used in computational estimation. Journal for Research in Mathematics Education, 20(2), 130-146.

Sriraman, B., \& Knott, L. (2009). The mathematics of estimation: Possibilities for interdisciplinary pedagogy and social consciousness. Interchange, 40(2), 205-223.

Star, J., \& Rittle-Johnson, B. (2009). It pays to compare: An experimental study on computational estimation. Journal of Experimental Child Psychology, 102(4), 408-426.

Star, J., Rittle-Johnson, B., Lynch, K., \& Perova, N. (2009). The role of prior knowledge in the development of strategy flexibility: The case of computational estimation. ZDM, 41(5), 569-579.

Subramaniam, K. (2014). Prospective secondary mathematics teachers' pedagogical knowledge for teaching the estimation of length measurements. Journal of Mathematics Teacher Education, 17(2), 177198.

Sunde, P. B., Petersson, J., Nosrati, M., Rosenqvist, E., \& Andrews, P. (2021). Estimation in the mathematics curricula of Denmark, Norway and Sweden: Inadequate conceptualisations of an essential competence. Scandinavian Journal of Educational Research. Advance online publication https://doi.org/10.1080/00313831.2021.1897881

Taillan, J., Ardiale, E., \& Lemaire, P. (2015). Relationships between strategy switching and strategy switch costs in young and older adults: A study in arithmetic problem solving. Experimental Aging Research, 41(2), 136156.

Tsao, Y.-L. (2013). Computational estimation and computational estimation attitudes of pre-service elementary teachers. US-China Education Review B, 3(11), 835-846.

Van Wyk, K., Backwell, A., \& Townson, A. (2015). A narrative literature review to direct spinal cord injury patient education programming. Topics in Spinal Cord Injury Rehabilitation, 21(1), 49-60.

Waring, G., Kirk, S., \& Fallon, D. (2020). The impact of chronic non-specific cough on children and their families: A narrative literature review. Journal of Child Health Care, 24(1), 143-160.

Waring, R., \& Penner-Wilger, M. (2017). Estimation of importance: Relative contributions of symbolic and non-symbolic number systems to exact and approximate calculation. Journal of Numerical Cognition, 2(3), 202-219.

Xenidou-Dervou, I., Van Luit, J., Kroesbergen, E., Friso-van den Bos, I., Jonkman, L., van der Schoot, M., \& van Lieshout, E. (2018). Cognitive predictors of children's development in mathematics achievement: A latent growth modeling approach. Developmental Science, 21(6), e12671. 
Xu, C., Wells, E., LeFevre, J.-A., \& Imbo, I. (2014). Strategic flexibility in computational estimation for Chinese- and Canadian-educated adults. Journal of Experimental Psychology: Learning, Memory, and Cognition, 40(5), 1481-1497.

Yaldo, L., \& Shamir, L. (2017). Computational estimation of football player wages. International Journal of Computer Science in Sport, 16(1), 1838.

Yang, D.-C. (2005). Number sense strategies used by 6 th $\square$ grade students in Taiwan. Educational Studies, 31(3), 317-333.

Yang, D.-C., \& Wu, S.-S. (2012). Examining the differences of the 8thGraders' estimation performance between contextual and numerical problems. US-China Education Review A, 12, 1061-1067.

\section{Corresponding Author:}

Paul Andrews

Stockholm University, Stockholm, Sweden

Email:paul.andrews@mnd.su.se 